\title{
Conceptualizations of the Heart in Jordanian Arabic: A Cognitive Perspective
}

\author{
Omar Bani Mofarrej (Corresponding author) \\ University of Jordan, Jordan \\ E-mail: Omarmofarrej@yahoo.com
}

Ghaleb Rabab'ah

University of Jordan, Jordan

Received: May 11, 2020

Accepted: June 26, 2020

Published: July 16, 2020

doi:10.5296/ijl.v12i4.17360

URL: https://doi.org/10.5296/ijl.v12i4.17360

\begin{abstract}
The present paper examines the metaphorical and metonymical conceptualizations of the heart in Jordanian Arabic (JA) within the framework of Conceptual Metaphor Theory developed by Lakoff and Johnson (1980). The main aim is to explore how the human heart is conceptualized in JA, and to test the applicability of the different general cognitive mechanisms proposed by Niemeier (2003 and 2008) to those found in JA. The data were extracted from Idioms and Idiomatic Expressions in Levantine Arabic: Jordanian Dialect (Alzoubi, 2020), and other resources including articles, dissertations and books of Arabic proverbs. The findings revealed that all the four general cognitive mechanisms suggested by Niemeier (2003 and 2008) are applicable to JA. The findings also showed that the similarity derives from the universal aspects of the human body, which lends tremendous support to the embodiment hypothesis proposed by cognitive linguists.
\end{abstract}

Keywords: Heart, Metaphor, Metonymy, Conceptual Metaphor Theory, Jordanian Arabic

\section{Introduction}

Despite the fact that different cultures and languages may vary in terms of which body part is considered the landing site of the human emotions, the heart is the container of emotions in Jordanian Arabic. In recent years, the conceptualization of internal body parts has raised a growing interest in cognitive linguistic research. A great deal of ink has been spilt on the study of heart idioms, metaphors and metonymies, and various studies have contributed to 
our understanding of the relationship between culture, body and language (e.g. Afreh, 2015; Badri, 2015; Maalej, 2008; Niemeier, 2003 and 2008; Swan, 2009; Yu, 2008; Qian, 2016).

From a cognitive perspective, heart-based idioms are linguistic manifestations that are motivated by some cognitive mechanisms like metaphor and metonymy (Kövecses, 2010). In this sense, we may assume that while heart idioms are linguistic manifestations that may vary considerably across different languages and cultures, metaphors and metonymies are conceptual in nature and, thus, might be shared by diverse languages. The heart in Jordanian Arabic (JA henceforth), as is the case in many languages, is considered the place where various emotions are said to reside. The present paper, therefore, investigates the metaphorical and metonymical conceptualizations of the heart in JA within the framework of Conceptual Metaphor Theory proposed by Lakoff and Johnson (1980).

The main objective of the study is to investigate the various types of emotions expressed in heart-based idiomatic expressions. Following Afreh (2015), the study also aims at testing the applicability of the different cognitive mechanisms proposed by Niemeier (2003 and 2008) to those found in JA. Niemeier (ibid) distinguishes four categorically different kinds of heart-based expressions, where the relation between the metaphorical expression and the underlying metonymy becomes weaker by degree. These mechanisms are: Heart as a metonymy for a person, Heart as A LIVING ORGANISM, Heart as an OBJECT OF VALUE, and Heart as a CONTAINER. In addition, Niemeier (2008) suggests that all these concepts overlap and compete with one another.

\section{Literature Review}

\subsection{Metaphor and Metonymy in Cognitive Linguistics}

In the traditional view, metaphors are no more than figures of speech. In this connection, Lakoff and Johnson (1980: 3) state that "metaphor is typically viewed as characteristic of language alone, a matter of words rather than thought and action". However, in cognitive linguistics, metaphor is an important cognitive tool that shapes the way we, as human beings, think about the world and, thus, is pervasive in language, thought and action (Lakoff and Johnson, 1980). Kövecses (2010: 4) points out that "[i]n the cognitive linguistics view, metaphor is defined as understanding one conceptual domain in terms of another conceptual domain". Thus, one conceptual abstract domain can be understood in terms of another conceptual concrete domain; the 'source' domain and the 'target' domain, respectively (Barcelona, 2003; Kövecses, 2010; Lakoff and Johnson, 1980). We use our experiences of the world to understand and conceptualize unfamiliar, abstract and/or new domains in terms of more concrete and familiar domains (Kövecses, 2010; Lakoff and Johnson, 1980 and 2003).

Two types of metaphor are distinguished; conceptual metaphors and linguistic metaphors. Rewiś-Łętkowska (2019) points out that linguistic metaphor are metaphors in language while conceptual metaphors are metaphors in mind. Conceptual metaphor, on the one hand, refers to the connection between two different concepts at the level of thought. One of the highly cited examples of this type of metaphor is the one that exists between the abstract concept of ARGUEMENT and the concrete concept of WAR. On the other hand, linguistic metaphors 
are the spoken or written manifestations of the conceptual metaphor. To show the difference between the two types of metaphors, consider the following examples adopted from Lakoff and Johnson (1980: 4):

\begin{tabular}{|c|c|}
\hline & ARGUEMNT IS WAR $\longrightarrow \quad$ Conceptual metaphor \\
\hline \multicolumn{2}{|l|}{ Your claims are indefensible. } \\
\hline \multicolumn{2}{|l|}{ He attacked every weak point in my argument. } \\
\hline \multirow{2}{*}{$\begin{array}{l}\text { His criticisms were right on target. } \\
\text { I demolished his argument. }\end{array}$} & \multirow[t]{2}{*}{ Linguistic metaphors } \\
\hline & \\
\hline \multicolumn{2}{|l|}{ I've never won an argument with him. } \\
\hline
\end{tabular}

In these examples, the abstract concept of ARGUMENT is understood in terms of the concrete concept of WAR. Although it is clear that no battle takes place, people seem to defend, win or lose the arguments. Yet, these expressions are partially structured by the concept of WAR. Thus, a conceptual metaphor like ARGUEMNT IS WAR is the main mechanism that motivates such linguistic realizations. This goes in line with Kövecses (2010: 7) who asserts that "it is the metaphorical linguistic expressions that reveal the existence of the conceptual metaphors".

Just like metaphor, metonymy involves an interaction between two conceptual domains, a source domain and a target domain (Croft and Cruse, 2004; Kövecses 2002, 2010, 2014; Kövecses and Radden, 1998; Lakoff and Johnson, 1980, 2003; Littlemore, 2015). For instance, Kövecses (2014) suggests that in metonymy an element in a domain, or frame provides mental access to another element within the same domain, or frame (p. 23). Further, Croft and Cruse (2004) point out that the content of the source domain is an ingredient of the construed target domain through processes of correspondence and blending. This means that while metaphor indicates the correspondence between two entities from two completely different domains, metonymy indicates the relationship between two entities within the same domain. In this sense, metonymy can be expressed in terms of a "stand-for" relation, where one conceptual domain stands for another. For instance, the linguistic expression "I am reading Shakespeare" is based on the metonymy PRODUCER STANDS FOR PRODUCT where the word Shakespeare; the vehicle entity, stands for one of Shakespeare's works; the target entity.

Barcelona (2011) pointed out that there are many controversial issues related to the study of metonymy in cognitive linguistics. He discussed these problematic properties of metonymy in the form of questions:

1. Is metonymy a relationship between "entities" or a relationship between "domains"?

2. Is metonymy necessarily connected to an act of reference?

3. What is meant by saying that metonymy is a "stand for" relationship?

4. Is metonymy a mapping? (See Barcelona, 2011: 9-36). 
In addition, he argued that there are other problematic properties that affect the standard criteria in the distinction between metaphor and metonymy. These are the following:

1. Cognitive domains often have fuzzy boundaries so that it is not always easy to know whether or not the source and the target domains are in the same superordinate domain.

2. A linguistic expression may often be interpreted, on the sole basis of context, background knowledge, or the purpose of the interpreter, as metaphorical or as metonymic.

3. Metaphor and metonymy very often interact in intricate patterns, a fact which complicates their distinction (Barcelona, 2011: 36).

Yet, he maintained that metonymy has a number of uncontroversial properties. He listed the following uncontroversial properties of metonymy proposed by cognitive linguists:

1. The fundamentally conceptual nature of metonymy;

2. The fact that it is experientially grounded;

3. The fact that it can be the root of certain cognitive models;

4. The fact that it involves experientially and conceptually connected, i.e., "contiguous", elements (emphasis is original) (Barcelona, 2011: 8).

\subsection{Studies on the Conceptualizations of the Heart}

The human heart is one of the internal body parts that has received considerable attention in cognitive linguistics research. In most cultures the heart serves as the source domain for the conceptualization of various emotions especially love and happiness (cf. Afreh, 2015; Baş, 2015; Goddard, 2008; Maalej, 2004, 2008; Niemeier, 2003, 2008; Yu, 2008). In this connection, Niemeier (2008: 351), for instance, points out that in English "[t]he prototypical emotion associated with the heart is romantic love, a uniquely human sensation". This is not to deny that negative emotions like hatred, sorrow, distress, just to mention some, are deeply felt in the heart as well. For instance, Baş (2015) maintains that HEART metaphors are prototypically associated with sadness in Turkish.

The human heart provides a good source domain for the conceptualization of various concepts. In many cultures, JA included, the heart is seen as the seat of emotions, beliefs and cultural values. Sharifian, Dirven, Yu and Niemeier (2008) introduced a volume to contribute to our understanding of cultures' conceptualizations of the heart and other internal body organs and how these internal body parts are centers to feeling, thinking and knowing, which are linguistically represented in diverse cultures.

Previous research has examined how the human heart is conceptualized in many languages including Arabic. Maalej (2008) examined the conceptualization of the human heart in Tunisian Arabic. He maintained that in present-day TA the heart is almost exclusively conceptualized as the seat of emotions and cultural values. For Maalej (ibid), the heart in TA is seen as a CONTAINER for emotions, people and objects can enter and leave it, which seems to be based on the IN-OUT image schema. The heart can also move upwards or 
downwards which might be motivated by the UP-DOWN image schema. In TA, on the one hand, various abstract concepts like love and sadness as well as cultural values like compassion, generosity, laziness, meanness are all based on the metaphoric conceptualization of the Tunisian heart. On the other hand, the metonymic conceptualization of the Tunisian heart is motivated by the conceptual metonymy THE HEART STANDS FOR THE PERSON. Maalej concluded that the heart in English is used to conceptualize a wider range of emotions, mental faculties, and cultural conceptualizations - equating the heart with the mind, thinking and understanding. In present-day TA, however, the /qalb/ 'heart' is dissociated from the mind, thinking, and understanding.

In Chinese, $\mathrm{Yu}$ (2008) examined the conceptualization of the human heart, which is traditionally conceptualized as the centre for cognitive activities. The Chinese "xin" is primarily used to denote the body part "heart", but it is also used to mean both "heart" and "mind". In addition, metonymic associations lead to the understanding of "xin" as thoughts, ideas, emotions and feelings. In ancient Chinese, the human heart was regarded as the reasoning organ, which unifies the human will, desire, emotion, reason and thought. This potential mental power of the heart results in the conceptual metaphor THE HEART IS THE RULER OF THE BODY, which suggests that the heart governs various types of intellectual and emotional activities. In this sense, "the concept of heart in English indicates that the Chinese conception of heart is in fact quite similar to that found in the Old and Middle English periods, when the English heart was also conceptualized as the seat of both feeling and thought" (Yu, 2008: 131).

Swan (2009) investigated the role of the heart in the conceptualization of human emotions in Old English and Middle/Early Modern English respectively. The historical data were extracted from dictionaries and other online resources. The study concluded that the pervasiveness of heart's occurrence in language proved its importance for the conceptualization of emotions and values. Further, the study findings revealed that the linguistic evidence from the history of English illustrates that heart metaphors have remained relatively stable over the centuries despite the very few changes. One of the most prominent changes is that "the heart has lost its sense of being a mind or soul in a wider sense, that is including intellectual capacity, and now merely refers to emotions of various sorts as well as moral values, especially love and kindness" (Swan 2009: 474).

The heart as a container of beliefs also has its roots in the religious discourse. In this connection, Badri (2015) used the conceptual metaphor paradigm to investigate the role of the social, cultural, physical and linguistic context in the production of novel and creative metaphorical conceptualization of the heart in Sufi religious discourse; particularly, in Al-Ghazali's The Revival of the Religious Sciences. The study showed that metaphorical conceptualizations of the heart are creative and innovative, and that the linguistic, social, cultural contexts play a significant role in facilitating such creativity.

Since the heart is seen as a container for emotions in various cultures, Baş (2017) analyzed Turkish idioms containing the Turkish words for 'heart' (yürek and kalp) to unveil how the heart is conceptualized in the minds of Turkish speakers. She aimed to establish a 
cognitive-cultural model for Turkish emotions. Idiomatic expressions containing the words 'kalp' and 'yürek' were taken from several dictionaries and analyzed based on an emotion categorization model she developed for Turkish. The findings revealed different conceptualizations of emotions, which include physical damage, fire, burden, agitation, force, and so on. The study demonstrated that 'yürek' and 'kalp' are productive source domains for their metaphoric conceptualization of a wide range of emotions in Turkish; e.g. SADNESS in expressions like (kalbiparçalanmak) "one's heart being shattered", and LOVE in (yüreğindensıcaksıcakalevçıkmak) "love hot flame comes out of someone's heart".

Other researchers have conducted contrastive studies to test the hypothesis that various abstract concepts are universally similar in the human conceptual systems. For instance, Pérez (2008) studied the conceptualizations of the heart in five languages: French, Italian and Spanish, English and German, in an attempt to establish a pattern of similarities and differences among these different cultures. The data were extracted from monolingual, bilingual dictionaries and dictionaries of idiomatic expressions. She found out that there are various similarities and differences in the conceptualizations of the heart in the languages under investigation. She argued that similarities can be attributed to the universal aspects of the human body, which supports the embodiment hypothesis proposed by cognitive linguists. For instance, the heart is the seat of feelings like: love, sincerity, sadness, kindness or generosity and courage, among others. Differences, on the other hand, are attributed to the different target domains to which the heart, the source domain, can be applied. For instance, the conceptual metaphor THE HEART IS THE STOMACH is only attested in French but not in the other languages. In addition, differences appear to be at the linguistic level where the same conceptual metaphor is linguistically elaborated differently.

Afreh (2015) compared and contrasted the metaphorical and metonymical conceptualization of the heart in Akan and English in an attempt to explore how the human experiences are expressed through the heart in Akan, the native language of Akan people in Ghana, looking for cross-conceptual, cross-linguistic or cross-cultural differences. The results of the study showed that there are no significant differences between Akan and English with respect to the heart metaphorical and metonymical conceptualizations. In the two languages, the conceptual metonymy THE HEART STANDS FOR THE PERSON forms the basis for many metaphorical mappings. For example, metaphors like THE HEART IS CHANGEABLE IN SIZE, THE HEART IS A SOLID and THE HEART IS A MOVABLE ENTITY are all based on the metonymy THE HEART STANDS FOR THE PERSON. Differences, on the other hand, appear in the elaboration of these metaphors. For example, in English the elaboration of the metaphor THE HEART IS A MOVABLE ENTITY is associated with love while in Akan the elaboration is associated with human attitudes of patience and impatience. This indicates that the differences in the conceptualizations of the heart are attributed to the cultural models embedded in the two languages.

Due to the fact that Chinese and English contain a large number of linguistic expressions that employ the human heart to conceptualize emotions and other abstract concepts, Qian (2016) compared the metonymy-based conceptual metaphors in these two languages. This cross-cultural comparison showed that, similar to English, there is some positive evidence for 
the metonymic base for metaphors in the Chinese culture. Further, the findings showed that the differences in the interpretations of the heart expressions are attributed to the specific cultural background.

Al-Saleh, Al-Shuaibi, Sharab and Al-Momani (in press) investigated the use and conceptualizations of the human head and heart in English and Spanish. The study aimed to explore similarities and differences with regard to the conceptual metaphors from which metaphorical expressions are derived, and the ways of conceptualizing these expressions. It also investigated the role of the human body-experiences in forming and conceptualizing the two body-based metaphorical expressions. The study showed that the two languages differ linguistically and conceptually. Despite this, the study showed that there is still a common way of conceptualizing the bodily-based human experiences through metaphor.

Previous research on heart-based metaphor and metonymy shows that the human heart as it is a rich source for conceptualization has been examined intensively. Reviewing previous research on metaphor and metonymy carried on heart-based idiomatic expressions, especially in the Arab World, has, however, shown that there are some limitations one can notice. Firstly, very few studies were conducted on the conceptualization of the heart in the Arab world (Bari, 2015 and Maalej, 2008), none of which is on JA. Secondly, most previous research conducted addressed a large number of body parts, and was based on a very limited number of expressions for each body part, which makes reference to all possible instances almost impossible. The present study, therefore, is hoped to bridge the gap in the literature, and contribute to our understanding of the human heart is conceptualized in the minds of JA speakers.

\section{Method}

\subsection{Data of the Study}

The data of the present study were the Jordanian Arabic idioms that contained the human heart. Native speakers of JA make use of a large number of heart-based idiomatic expressions to conceptualize various abstract concepts. Some of these expressions are still used in the standard forms (e.g. من أعماق قلبي /min Pacma:g qalb-i/, from the bottom of my heart) while others are exclusively used in Jordanian spoken Arabic (e.g. قلبه أخضر /qalb-u Pkhdar/, literally "his heart is green").

\subsection{Data Collection and Analysis}

The data of the present study were mainly extracted from Idioms and Idiomatic Expressions in Levantine Arabic: Jordanian Dialect (Alzoubi, 2020), and other resources including articles, dissertations and books of Arabic proverbs. Idioms that include the word "qalb" (heart) and its derivative forms /qalb-i; qalb-u; qalb-ha/ were collected. The data were then analyzed to test the applicability of the cognitive mechanisms proposed by Niemeier (2003) and Niemeier (2008) to those present in JA, namely, Heart as a metonymy for a person, Heart as A LIVING ORGANISM, Heart as an OBJECT OF VALUE, and Heart as a CONTAINER. 


\section{Ml Macrothink}

\section{Findings}

The analysis of the idioms under investigation has shown that all the four major metonymic and metaphoric mappings identified by Niemeier (2003 and 2008) do exist in JA as well. This could be attributed to the fact that they are all general cognitive mechanisms that might be shared by diverse languages and cultures. In what follows, we present a detailed discussion of these four general cognitive mechanisms with examples from JA.

\subsection{The Heart Is a Container}

Native speakers of JA make use of various heart-based linguistic metaphors to conceptualize emotions. In this respect, Csábi (4004: 50) points out that "the most frequent conceptual metaphor that motivates English heart idioms is EMOTIONS ARE IN THE HEART", which is the case in JA as well. Prepositions like /bi, fi/ (in) and / $\mathrm{min} /$ (from) suggest that emotions are conceptualized as substances in a container. In this sense, the conceptualization of emotions is grounded in our bodily experience and motivated by the basic inferences derived from the conceptual structure of the CONTAINER image schema (Cervel, 2001: 258-9). Thus, the CONTAINER image schema is attested in JA in expressions like those below:

1. a. من أعماق (قاع, جوّا) قلبي

min Pacma:q (qa:c, juw-wa) qalb-i

from bottom heart-my

From the bottom of my heart

b. الكلام طالع من قلبي

hal-kala:m talic min qalb-i

This speech comes out from heart-my

From one's heart

c. اللي بقلبه ع راس لسانه

Pil-li b-qalb-u ca ra:s ilsa:nuh

What in-heart-his on tip-tongue-his

What is in his heart is on the tip of his tongue

In the expression in 1a, the heart is seen as a CONTAINER WITH GREAT DEPTH. This goes nicely with Niemeier $(2003,2008)$ who points out that the heart is visualized as having a bottom, /qa: ${ }^{\mathrm{c}}$ and $\mathrm{Pa}^{\mathrm{c} m a: q /}$ in JA, in which one's innermost and sincere feelings are stored. In $1 \mathrm{~b}$ and $\mathrm{c}$, feelings are seen as substances that come out of the container moving upward to reach an area at the tip of the tongue ready to be spoken out. In all the three expressions above, sincere feelings go out of the heart, upwards, which means that the IN/OUT and the UP/DOWN image schemas are also activated by such expressions. 


\section{MInstitute ${ }^{\text {Macrothink }}$}

In line with Maalej (2008), containers in JA can also be full or empty of some content, anger and mercy for instance, as shown in the following examples:

2. a. قلبي مليان على فلان

qalb-i malya:n cala fla:n

heart-my full on $\mathrm{x}$

My heart is full with anger

b. طلعت كل اللي بقلبي عليه

tal-lacit kul-1 il-li b-qalb-i

Pour out-I all that in heart-my

I poured out all my anger

c. ما فيه بقلبه رحمة

ma: fi b-qalb-u rahmah

Not no Heart-his mercy

There is no mercy in his heart

When a container is full of content and can receive no more, it pours out as it cannot take more. For instance, in $2 \mathrm{a}$ above, the heart is conceptualized as a container that is full (of anger). In $2 b$, on the other hand, the heart is deliberately getting emptied of its content (anger in this case as well) while in $2 \mathrm{c}$ the heart is visualized as being completely empty of its content, mercy in this case.

\subsection{The Heart as a Living Organism}

The data also showed that the heart in JA is also visualized as a LIVING ORGANISM that can work independently as AN AUTONOMOUS ENTITY. As example 1a below shows, the heart is seen as an autonomous entity that changes position because of some outer influence. In this sense, the heart is visualized as an entity that is jumping with happiness and joy. In $1 \mathrm{~b}$, it is seen as A MOVABLE OBJECT that changes position downward as a sign of FEAR. Following Maalej (2008), this kind of downward movement is motivated by the conceptual metaphor DOWN IS BAD. In 1c, on the other hand, the heart is visualized as a human being that can sting one to warn him/her about something wrong going on. In addition, one of the most true facts about living things is that they will die sooner or later. This fact is exemplified in expression 1d below. When something is described as being dead, it was, then, once a live. The heart is conceptualized as being dead, which symbolizes negative emotions like lack of sympathy and caring for the feeling of others and/or positive feelings like courage and lack of fear. Consider the following context to clarify this idea:

Context 1: Two friends A and B are talking about a third person describing him negatively because he lacks sympathy.

A. حكيت ل ناصر عن حادث السيارة وما تأثر.

hakayt la Nasser can ha:dith is-say-ya:ra w ma t?ath-thar 


\section{Macrothink

I talked to Nasser about the car accident, but he didn't feel sorry

B. يارجل هذا قلبه ميت

ya: rajul hadha qalb-u may-yit

Oh man! His heart is dead (lack of sympathy and caring)

Context 2: Two friends $\mathrm{A}$ and $\mathrm{B}$ are talking about a third person describing him positively because he is courageous.

A. لما رحنا عالغابة مبار ح أنا متت من الخوف لكن أحمد ما كان خايف

lam-ma ruhna cala l-qhaba mbarihh ?ana mutit min il-khawf, la:kin

ahmad ma kan kha:yif

When we went to the forest yesterday, I was scared to death, but Ahmad wasn't.

B. B.

ya: rajul hadha qalb-u may-yit wala bicrif il-khawf

Oh man! His heart is dead and he doesn't know what fear is (lack of fear)

Let us now go back to our examples:

1.a. نط قلبه من محله

nat- $\underline{t}$ qalb-u min mahal-luh

Jumpd heart-his from place-its

His heart jumped with joy

b. قلبه صار بين رجليه

qalb-u sa:r bayn rijlayh

Heart-his becomes between legs-his

He was scared to death

c. قلبي نقزني

qalb-i naqazni

Heart-my stings-me

My heart stings me

d. قلبه ميّت

qalb-u may-yit

Heart-his dead

He is heartless/ hardhearted 


\section{Macrothink}

International Journal of Linguistics

ISSN 1948-5425

2020, Vol. 12, No. 4

The heart in JA can be also visualized as an autonomous entity, but not as a living organism. It is seen as a sofa on which people sit as expression 2 below indicates:

2. قاعد على قلبه

qa:cid cala qalb-uh

Sit(I) on heart his.

I am sitting on his heart

Restrain someone's freedom

However, the expression in 2 above is used to show that one can prevent others from acting freely by sitting on their hearts.

\subsection{The Heart Stands for the Person}

In JA, almost all the expressions that contain the heart are partially motivated by the conceptual metonymy THE HEART STANDS FOR THE PERSON - the only exception is when we refer to the heart as an autonomous entity. This means that various conceptual mechanisms work jointly to motivate a single body-based expression (Foolen, 2008; Kövecses, 2010). To avoid repetition, we present some examples that are not presented previously to show the metonymic conceptualizations of the heart.

Similar to Tunisian Arabic, the heart in JA is seen as A CHANGEABLE AND MANUPLIABLE OBJECT. For example, compassion is conceptualized as softness of the heart while cruelty is conceptualized as hardness of the heart (Maalej, 2008).

1. a. قلبه رهيّف

qalb-u rhay-yif

Heart-his soft

He is softhearted

b. قلبه قاسي

qalb-u qa:si

Heart-his hard

His heart is hard

c. قلبه حجر

qalb-u hajar

Heart-his stone

His heart is stone 
Softness of the heart is correlated with sensitivity, compassion and interest for others feelings as the expression in 1a shows. The hardness of the heart, on the other hand, is associated with lack of mercy, compassion, sympathy and interest for others as the expressions $1 \mathrm{~b}$ and $\mathrm{c}$ indicate. In $1 b$ and $c$, the heart is conceptualized as a solid material to refer to negative emotions - THE HEART IS A SOLID. In addition, the heart is seen as CHANGEABLE IN SIZE to accommodate a variety of positive and good feelings as shown in 2 below. This goes nicely with Niemeier (2003) who maintains that "in some people, the container is conceptualized as being bigger than normal, meaning that their hearts are especially full of positive emotions, that they are friendly, altruistic, empathetic, and give help generously" ( $\mathrm{p}$. 200).

2. قلبه كبير

qalb-u kbeer

Heart-his big

His heart is big

However, the data has shown that the heart in JA is not only conceptualized as changeable in size, but also as CHANGEABLE IN COLOR. The manipulation and change of the heart's color describes the character traits of the person being described. For instance, the expression in example 3a below is used to describe an old man who acts, dresses up or behaves just like young people; i.e., a person who loves women and keeps trying to look younger in their eyes (Al-Adaileh, 2012). The choice of the color 'green' is motivated by Jordanians' conventional knowledge that this color is usually associated with nature and life; i.e. it is the color of plants, leaves on trees and grass. The color white, on the other hand, is associated with purity, innocence and tolerance. Therefore, the expression in $3 \mathrm{~b}$ symbolizes a person who forgives others quiet quickly. It is also used to describe a person who does not hide any evil feelings toward others; and a person who is tolerant. In 3c, on the other hand, the color term 'black' is used to show the negative character trait of being intolerant. It also indicates hatred and lack of forgiveness. Maalej (2008: 416) argues that the correlation of whiteness with tolerance and blackness with intolerance arises from the conceptual metaphors WHITE IS GOOD and BLACK IS BAD.

3. a. قلبه أخضر

qalbu Pakhdar

Heart-his green

his heart is green

b. قلبه أبيض

qalbu Pabyad

heart-his white

His heart is white 


\section{$\Lambda$ Macrothink}

c. قلبه أسود

qalb-u Paswad

heart-his black

His heart is black

\subsection{The Heart as an Object of Value}

Similar to English, the heart in JA as shown in the data analyzed is seen as an object of value as well. Consequently, native speakers of JA attribute the properties of objects to the heart. Afreh (2015) points out that the heart in Akan is considered to be a treasure or something of a heart value to its owner and to others, which seems to be the case in JA as well. The expression in 1a below captures this:

1. a. كسب قلوب الناس

kisib qlu:b in-na:s

Won-he hearts people

He won the hearts of people

b. كسر قلبه

Kasar qalbuh

broke heart-his

He broke his heart

In $1 \mathrm{a}$, there is a winner in the source domain and something to be won in the target. When someone wins, he/she usually gains valuable objects, which may suggest that the heart is metaphorically conceptualized as A VALUABLE OBJECT. Yet, in the case at hand, the metonymical heart refers to the emotion; i.e. it is not the heart but the feelings seated in the heart that have been won. This in mind, the metonymical basis for the metaphorical understanding of this expression is based on the relation between the heart and the feelings. On the other hand, the use of the verb /kasar/ (broke) in example 1b presupposes lenity and mildness of the heart because lenient and fragile materials are more likely to be easily broken as opposed to hard materials.

\section{Conclusion}

The present paper has demonstrated that the heart in JA is a productive source domain for the conceptualization of emotions. Since the heart is the seat where emotions are said to reside, it is natural that heart conceptualizations are affected by these emotions (Maalej, 2008). Similar to English, the heart in JA is conceptualized as a CONTAINER FOR EMOTIONS. Emotions, in this sense, are thought of as entities that move up and down, which suggests that UP/DOWN image schema is motivated by the container image schema. In addition, emotions can get in or out of the container, which suggests the existence of IN/OUT image schema. 
The heart is also visualized as a LIVING ORGANISM that can work as an AUTONOMOUS ENTITY. The CHANGEABILITY of the heart's SIZE and COLOR in JA also offers various metaphorical conceptualizations that profile emotions. Thus, the heart in JA is visualized as CHANGEABLE IN COLOR, which is not discussed by Niemeier (2003 and 2008). This may suggest that the conceptualization of the heart "is not just embodied but culturally embodied" (Maalej, 2008: 223). In most of the examples provided in the database, the heart is used to refer to the person as whole which indicates that the conceptual metonymy THE HEART STANDS FOR THE PERSON underlies these expressions.

\section{References}

Afreh, E. (2015). The Metonymic and Metaphoric Conceptualisations of the Heart in Akan and English. Legon Journal of the Humanities, 26, 38-57. https://doi.org/10.4314/ljh.v26i1.3

Al-Adaileh, B., \& Al-Abbadi, R. (2012). The pragmatic implications of metonymical body-based idioms in Jordanian Arabic. Argumentum, 8, 73-91.

Al-Saleh, T., et al.. (n.d.). A Cognitive Analysis of Head and Heart Metaphors in English and Spanish. International Journal of Arabic-English Studies, 20(1), 220.

Badri, A. (2015). Metaphorical Creativity in the Conceptualization of the Heart in Al-Ghazali's The Revival of the Religious Sciences (Ihyā' 'ulūm ad-dīn). International Journal of Humanities and Culture, 2(3), 94-115.

Barcelona, A. (2003). On the Plausibility of claiming a metonymic motivation for conceptual metaphor. In A. Barcelona (Ed.), Metaphor and metonymy at the crossroads: A cognitive perspective (pp. 1-28). Berlin Moutonde Gruyter.

Barcelona, A. (2011). Reviewing the properties and prototype structure of metonymy. In R. Benczes, A. Barcelona, \& F. J. Ruiz de Mendoza Ibáñez (Eds.), Defining Metonymy in Cognitive Linguistics: Towards a Consensus View pp. 7-57). Amsterdam: John Benjamins. https://doi.org/10.1075/hcp.28.02bar

Baş, M. (2015). Conceptualization of Emotion through Body part Idioms in Turkish: A Cognitive Linguistic Study. Unpublished PhD Dissertation, Ankara, Turkey.

Baş, M. (2017). The metaphoric conceptualization of emotion through heart idioms in Turkish. Cognitive Semiotics, 10(2), 121-139. https://doi.org/10.1515/cogsem-2017-0006

Crevel, S. (2001). A cognitive approach to the role of body parts in the conceptualization of Emotion Metaphors (pp. 245-260). Epos, XVII.

Croft, W., \& Cruse, A. (2004). Cognitive Linguistics. Cambridge, Cambridge University Press. https://doi.org/10.1017/CBO9780511803864

Csábi, S. (2004). Alternative Conceptualization in English and Hungarian Idioms. Unpublished PhD Dissertation. Eötvös Loránd University, Budapest.

Foolen, A. (2008). The heart as a source of semiosis: The case of Dutch. In F. Sharifian, R. Dirven, N. Yu, \& S. Niemeier (Eds.), Culture, body, and language: Conceptualizations of 


\section{Macrothink}

International Journal of Linguistics

ISSN 1948-5425

2020, Vol. 12, No. 4

internal body organs across cultures and languages (pp. 395-428). Berlin: Mouton de Gruyter.

Goddard, C. (2008). Contrastive semantics and cultural psychology: English heart vs. Malay hati. In F. Sharifian, R. Dirven, N. Yu, \& S. Niemeier (Eds.), Culture, body, and language: Conceptualizations of internal body organs across cultures and languages (pp. 75-102). Berlin: Mouton de Gruyter.

Kövecses, Z. (2002). Metaphor: A practical introduction (1sted.). Oxford: Oxford University Press.

Kövecses, Z. (2010). Metaphor: A practical introduction (2nded.). Oxford: Oxford University Press.

Kövecses, Z. (2014). Metaphor and metonymy in the conceptual system. In P. Frank, K. Zoltán, V. Stefanie, \& K. Sonja (Eds.), Cognitive Explorations into Metaphor and Metonymy (pp. 15-35).

Kövecses, Z., \& Radden, G. (1998). Metonymy: Developing a cognitive linguistic view. Cognitive Linguistics, 9(1), 37-77.https://doi.org/10.1515/cog1.1998.9.1.37

Lakoff, G., \& Johnson, M. (1980). Metaphors We Live by. Chicago and London: The University of Chicago Press.

Lakoff, G., \& Johnson, M. (2003). Metaphors we live by. Chicago, IL: University of Chicago Press. https://doi.org/10.7208/chicago/9780226470993.001.0001

Littlemore, J. (2015). Metonymy: Hidden Shortcuts in Language, Thought and Communication. Cambridge University Press, Cambridge. https://doi.org/10.1017/CBO9781107338814

Maalej, Z. (2004). Figurative language in anger expression in Tunis-Arabic: An extended view of embodiment. Metaphor and Symbol, 19(1), 51-75. https://doi.org/10.1207/S15327868MS1901_3

Maalej, Z. (2008). The heart and cultural embodiment in Tunisian Arabic. In F. Sharifian, R. Dirven, N. Yu, \& S. Niemeier (Eds.), Culture, body, and language: Conceptualizations of internal body organs across cultures and languages (pp. 395-428). Berlin: Mouton de Gruyter.

Niemeier, S. (2003). Straight from the heart: Metonymic and metaphorical explorations. In A. Barcelona (Ed.), Metaphor and metonymy at the crossroads: A cognitive perspective (pp. 195-213). Berlin, Germany: Mouton de Gruyter.

Niemeier, S. (2008). To be in control: kind-hearted and cool-headed. The head-heart dichotomy in English. In F. Sharifian, R. Dirven, N. Yu, \& S. Niemeier (Eds.), Culture, body, and language: Conceptualizations of internal body organs across cultures and languages (pp. 349-372). Berlin: Mouton de Gruyter. 


\section{Macrothink}

International Journal of Linguistics

ISSN 1948-5425 2020, Vol. 12, No. 4

Pérez, R. (2008). A Cross-Cultural Analysis of Heart Metaphors. Revista Alicantina de Estudios Ingleses, 21, 25-56. https://doi.org/10.14198/raei.2008.21.03

Qian, L. (2016). Metonymic-Based Metaphor-A Case Study on the Cognitive Interpretation of "Heart" in English and Chinese. Higher Education Studies, 6(4), 131-137. https://doi.org/10.5539/hes.v6n4p131

Rewiś-Łętkowska, A. (2019). The linguistic, conceptual and communicative dimension of metaphor: A corpus study of conversational Polish. Journal of Pragmatics, 153, 80-91. https://doi.org/10.1016/j.pragma.2019.03.005

Sharifian, F., Dirven, R., Yu, N., \& Niemeier, S. (2008). Culture, Body, and Language: Conceptualizations of Internal Body Organs across Cultures and Languages. Berlin; Boston: De Gruyter Mouton. https://doi.org/10.1515/9783110199109

Swan, T. (2009). Metaphors of body and mind in the history of English. English Studies, 90(4), 460-475. https://doi.org/10.1080/00138380902796292

$\mathrm{Yu}, \mathrm{N}$. (2008). The Chinese heart as the central faculty of cognition. In F. Sharifian, R. Dirven, N. Yu, \& S. Niemeier (Eds.), Culture, body, and language: Conceptualizations of internal body organs across cultures and languages (pp.131-168). Berlin: Mouton de Gruyter.

\section{Copyrights}

Copyright for this article is retained by the author(s), with first publication rights granted to the journal.

This is an open-access article distributed under the terms and conditions of the Creative Commons Attribution license (http://creativecommons.org/licenses/by/4.0/) 